\title{
Pelaksanaan Program Inisiasi Menyusu Dini Di Wilayah Kerja Puskesmas Lubuk Buaya Kecamatan Koto Tangah
}

\author{
Afrah Diba Faisal ${ }^{1}$, Joserizal Serudji ${ }^{2}$, Hirowati Ali ${ }^{3}$
}

\section{Abstrak}

Inisiasi menyusu dini (IMD) atau early latch on adalah kesempatan yang diberikan kepada bayi segera setelah lahir dengan cara meletakkan bayi di perut ibu, kemudian dibiarkan untuk menemukan puting susu ibu dan menyusu hingga puas. Tujuan: Mendeskripsikan pelaksanaan program IMD di wilayah kerja Puskesmas Lubuk Buaya kecamatan Koto Tangah. Metode: Penelitian ini merupakan evaluation research dengan pendekatan kualitatif menggunakan strategi management-oriented systems models, dengan 4 informan utama dan 9 informan triangulasi. Pengumpulan data dilakukan dengan wawancara mendalam, dokumentasi dan observasi. Hasil: Bidan sudah cukup berkualitas dan kompeten dalam pelaksanaan IMD, tidak ada perencanaan dana IMD secara khusus karena IMD merupakan pelayanan persalinan, sarana dan prasarana sudah cukup baik, perencanaan kegiatan IMD sudah cukup baik dilakukan saat ibu memeriksakan kehamilan dan di kelas ibu hamil, pengorganisasian program IMD belum optimal masih ada yang belum tersosialisasikan secara khusus, pelaksanaan kegiatan IMD belum cukup baik, bidan tidak melaksanakan IMD sesuai protap, monitoring dan evaluasi pelaksanaan program IMD langsung dalam bentuk pencatatan dan pelaporan. Simpulan: Bidan belum mematuhi protap IMD sehingga perlu diberikan motivasi agar melaksanakan sesuai protap dan evaluasi keseluruhan program IMD oleh Puskesmas Lubuk Buaya.

Kata kunci: pelaksanaan, program IMD, bidan

\section{Abstract}

Early breastfeeding initiation (IMD) or early latch on is a given opportunity to baby after born by lying the baby on mom's stomach, afterward let the baby attempts to find his way to mom's breast and suckles until satisfied. Objectives: To described the implementation of early breastfeeding initiation programs in the working area of Lubuk Buaya Health Center in Koto Tangah. Methods: It was an evaluation research with qualitative approaching by using a management-oriented systems model strategy, with four main informants and nine triangulation informants. The data collecting conducted by deep interviews and observation. Results: The quality of midwives was good enough, namely they have education in midwifery and have done the IMD training, The fund for purposing the IMD program did not exist specifically, but funding for health services in health scope of Padang city comes from the regional budget of the province and the city itself. The organizing of the IMD program was not optimal because there are still those that have not been socialized. The implementation of IMD activities was not good enough, the midwives did not conduct IMD as according to the rules. Monitoring and evaluating of IMD program was in the form of recording and reporting. Conclusion: Midwives have not adhered to motivation to the IMD protocol so it is necessary to motivate the implementation midwifes to carry out by the protocol and evaluation of all programs by the Lubuk Buaya Health Center. Keywords: implementing, IMD program, midwives

Affiliasi penulis: 1. Universitas Baiturrahmah, 2. Bagian ObstetriGinekologi Fakultas Kedokteran Universitas Andalas Padang (FK Unand), 3. Bagian Biokimia FK Unand.
Korespondensi: Afrah Diba Faisal, Email: Afrahdiba@yahoo.com HP: 081374716815 


\section{PENDAHULUAN}

Inisiasi Menyusu Dini (IMD) adalah salah satu program Departemen Kesehatan Republik Indonesia, yang memberikan rangsangan awal dimulai pemberian Air Susu lbu (ASI) secara dini, dan diharapkan berkelanjutan selama enam bulan pertama. Kegagalan IMD dan pemberian ASI Ekslusif pada periode tersebut, berpotensi menimbulkan defisiensi zat gizi pada bayi, serta memungkinkan terjadi status gizi kurang, yang berujung pada penurunan poin kecerdasan intelektual bayi dan menjadi ancaman terhadap sumber daya manusia pada masa mendatang. ${ }^{1}$

Berdasarkan profil Kesehatan Indonesia, Angka Kematian Bayi (AKB) di Indonesia tahun 2012 adalah sebesar 32 per 1000 Kelahiran Hidup (KH). Survei Penduduk Antar Sensus (SUPAS) tahun 2015 menyatakan AKB di Indonesia adalah sebesar 22,23 per 1000 kelahiran hidup dan telah mencapai target Millenium Development Goals (MDGs), sebesar 23 per 1000 Kelahiran Hidup. ${ }^{2}$

IMD sangat berperan dalam tercapainya Sustainable Development Goals (SDGs) khususnya pada tujuan ketiga yakni kesehatan dan kesejahteraan yang baik dengan target menurunkan angka kematian neonatus sebesar 12 per 1000 kelahiran hidup. ${ }^{3}$

Hasil laporan Dinas Kesehatan Provinsi Sumatera Barat tahun 2016, pemberian Asi Ekslusif pada bayi umur 0-6 bulan sejumlah 4305(72,2\%) dari 5961 bayi serta di Lubuk Buaya pemberian ASI Ekslusif sejumlah 398(71,97\%) dari 553 bayi. Angka ini masih kurang dari target nasional yaitu $80 \%$. Hal ini dikarenakan IMD dapat meningkatkan cakupan ASI Eksliusif sampai 59\%. Selain itu IMD dapat menurunkan kematian bayi sebesar $22 \% .^{4}$

IMD memberikan banyak manfaat untuk kesehatan ibu maupun bayi baru lahir. Manfaat untuk ibu IMD terbukti dapat meningkatkan kadar hormon oksitosin dan mempercepat involusi uteri 2 jam post partum dan mempersingkat waktu pelepasan plasenta sehingga dapat mencegah terjadinya perdarahan post partum yang menjadi salah satu penyebab terbesar kematian ibu di seluruh dunia termasuk Indonesia. ${ }^{5}$ Manfaat untuk bayi menurut beberapa penelitian menyusui segera dalam 1 jam pertama kelahiran dapat mencegah kematian bayi dalam satu bulan pertama hingga $22 \%$ sedangkan menyusui pada hari pertama lahir (24 jam) dapat menekan angka kematian bayi hingga $16 \%,{ }^{6}$ mencegah kematian pada bayi dengan berat badan lahir rendah (BBLR), serta mencegah kematian akibat diare dan pneumonia yang menjadi salah satu penyebab utama kematian bayi. ${ }^{7}$

Bidan sebagai ujung tombak tenaga kesehatan yang sangat dekat dengan ibu dan masyarakat pada umumnya memiliki peranan yang sangat penting dalam manajemen laktasi yang diawali dengan berlangsungnya proses IMD. Dalam 10 indikator program Baby-Friendly Hospital Initiative (BFHI) yang digagas WHO untuk mendukung program pemberian Air Susu Ibu (ASI) secara dini, bidan juga sangat diperlukan untuk berpartipasi secara penuh. ${ }^{8}$

Puskesmas Lubuk buaya merupakan salah satu wilayah puskesmas di Kecamatan Koto Tangah dengan jumlah kelahiran tertinggi Tahun 2015 yaitu sebanyak 1787 kelahiran hidup. Cakupan kunjungan neonatal lengkap sebanyak 1386, serta jumlah bayi yang diberikan ASI Ekslusif usia 0-6 bulan sebanyak $398(71,97 \%){ }^{4}$

Cakupan Pelaksanaan IMD masih sangat rendah. Berdasarkan studi pendahuluan yang peneliti lakukan pada 10 BPM (Bidan Praktik Mandiri) dari 32 BPM yang ada di wilayah Puskesmas Lubuk Buaya di Kecamatan Koto Tangah, menyebutkan bahwasanya banyak faktor yang mempengaruhi tidak terlaksananya IMD secara efektif. Salah satu dilihat dari kurangnya pelayanan konseling laktasi dan dukungan dari petugas, serta belum optimalnya komitmen puskesmas dan penolong persalinan untuk selalu melakukan IMD pada bayi baru lahir.

Penelitian ini bertujuan untuk mengetahui lebih lanjut tentang pelaksanaan program IMD di wilayah kerja Puskesmas.

\section{METODE}

Jenis penelitian ini adalah evaluation research dengan pendekatan kualitatif menggunakan strategi management-oriented systems models. Jumlah sampel 14 orang terdiri dari 3 kelompok triangulasi, informan kunci 2 orang, informan utama 3 orang, informan tambahan 9 orang. Waktu dari bulan 
November 2018 sampai dengan Februari 2019 di wilayah kerja Puskesmas Lubuk Buaya Padang. Telah dilaksanakan wawancara mendalam dan merekam menggunakan perekam suara serta pembuatan catatan lapangan, melakukan pemindahan dari alat perekam suara dan dilanjutkan dengan penyusunan transkrip data dan melakukan pengkodean kemudian pemahaman unit dan mengkategorikan kemudian melanjutkan untuk menganalisa dan menentukan kesimpulan.

\section{HASIL}

Penelitian telah dilakukan untuk mengetahui lebih lanjut tentang pelaksanaan program IMD di wilayah kerja Puskesmas dilakukan terhadap 13 informan penelitian terdiri dari dokter dan bidan yang menangani asuhan persalinan normal dengan IMD sebagai salah satu tahapannya, Pimpinan Puskesmas, penanggung jawab KIA-KB, Tokoh Masyarakat, ibu bersalin dan keluarga ibu bersalin. Karakteristik dari masing-masing informan pada penelitian ini

Tabel 1. Karakteristik informan utama

\begin{tabular}{lllll}
\hline Kode & Nama & Umur & Jabatan & Pddkn \\
\hline If 2a & dr. S & 38 & Dokter & Dokter \\
If 2b & L & 45 & Bidan & DIV-Bidan \\
If 2c & K & 42 & Bidan & S2 M.Keb \\
If 2d & A & 43 & Bidan & DIII keb \\
& & & BPM & \\
& & & &
\end{tabular}

Hasil Tabel 1 dapat dilihat bahwa karakteristik dari informan utama berumur antar 38 - 45 tahun, jadi informan masih berada pada usia produktif. Informan utama memiliki pendidkan minimal DIII Kebidanan

Tabel 2. Karakteristik informan

\begin{tabular}{llcll}
\hline Kode & Nama & Umur & Jabatan & Pddkn \\
\hline If 1a & dr. D & 50 & $\begin{array}{l}\text { Pimpinan } \\
\text { Puskesmas }\end{array}$ & dokter \\
& & & PJ KIA - KB & S2- \\
If 1b & L & 46 & M.Keb \\
& & & &
\end{tabular}

Hasil Tabel 2 dapat dilihat bahwa karakteristik informan penelitian yaitu pimpinan puskesmas berumur 50 tahun dan memiliki pendidikan terakhir S1 dan untuk penanggung jawab KIA-KB berumur 46 tahun dan memiliki pendidikan S2 kebidanan. Umur informan penelitian masih dalam usia produktif.

Tabel 3. Karakteristik informan (non kesehatan)

\begin{tabular}{|c|c|c|c|c|c|}
\hline & Kode & Nama & Umur & Jabatan & Pddkn \\
\hline 1 & If $3 a$ & $\bar{A}$ & & $\begin{array}{l}\text { Pengacara } \\
\text { (TOMA) }\end{array}$ & $\begin{array}{l}\text { S1 } \\
\text { hukum }\end{array}$ \\
\hline 2 & If $3 b$ & $\mathrm{~N}$ & 21 & $\begin{array}{l}\text { Ibu } \\
\text { bersalin } \\
\text { PKM }\end{array}$ & SMA \\
\hline 3 & If $3 c$ & $S$ & 45 & $\begin{array}{l}\text { Keluarga } \\
\text { bulin PKM }\end{array}$ & SMP \\
\hline 4 & If $3 d$ & $\mathrm{~N}$ & 22 & $\begin{array}{l}\text { Ibu } \\
\text { bersalin } \\
\text { Pustu }\end{array}$ & SMA \\
\hline 5 & If $3 e$ & E & 55 & $\begin{array}{l}\text { Keluarga } \\
\text { bulin } \\
\text { Pustu }\end{array}$ & SMA \\
\hline 6 & If $3 f$ & M & 26 & $\begin{array}{l}\text { Ibu } \\
\text { bersalin } \\
\text { BPM }\end{array}$ & SMK \\
\hline 7 & If $3 g$ & A & 30 & $\begin{array}{l}\text { Keluarga } \\
\text { bulin BPM }\end{array}$ & SMA \\
\hline
\end{tabular}

Hasil Tabel 3, pemilihan 7 informan (non kesehatan) secara accidental yaitu memilih tokoh masyarakat, keluarga ibu bersalin dan ibu bersalin yang baru saja melakukan persalinan yang masih berada di klinik bersalin wilayah kerja puskesmas lubuk buaya. Dari data tersebut dapat dilihat bahwa karakteristik informan tokoh masyarakat yaitu berumur 70 tahun dan memiliki pendidikan S1 dengan pekerjaan pengacara, ibu bersalin yaitu berumur 21 26 tahun dan memiliki pendidikan SMA dan keluarga ibu bersalin berumur $30-55$ tahun dan minimal SMP.

\section{PEMBAHASAN}

\section{INPUT}

\section{Sumber Daya Manusia (SDM)}

Puskesmas sebagai unit pelaksana pembangunan kesehatan di wilayah merupakan ujung tombak dalam pelayanan kesehatan, terutama dalam pelayanan kesehatan ibu hamil, bayi dan balita. Keberhasilan ini sangat dipengaruhi oleh penataan dan pengelolaan tenaga kesehatan khususnya bidan untuk dapat melaksanakan kegiatan pokok puskesmas yang berhubungan dengan kesehatan ibu. 
Permenkes No.75 tahun 2014 yang menyangkut dengan puskesmas secara keseluruhan, didalamnya diatur tentang SDM puskesmas secara keseluruhan termasuk salah satunya mengenai tenaga kebidanan. Dengan adanya Permenkes maka puskesmas melakukan analisis jabatan dengan BKD bahwa jumlah tenaga kesehatan yang akan melayani ibu hamil dirasa kurang dan tidak sesuai dengan standar. ${ }^{4}$

Kekurangan tenaga mengakibatkan beban kerja bidan meningkat. Bidan memiliki peran dan tugas ganda, tidak hanya melayani ibu hamil, persalinan bahkan bidan juga menjadi petugas administrasi. Penambahan beban kerja diluar tupoksi juga berpengaruh terhadap motivasi bekerja bidan. Pada penelitian ini jumlah sumber daya manusia di Puskesmas Lubuk Buaya kota Padang pada pelaksanaan program IMD sudah terpenuhi begitu juga dengan kompetensi dan kualitas, seluruh petugas IMD adalah bidan dengan pendidikan D3 Kebidanan dan sudah mendapatkan pelatihan Asuhan Persalinan Normal. $^{9}$

Penelitian menyebutkan bahwa untuk meningkatkan kualitas pelayanan harus menyusun rencana dalam meningkatkan kompetensi, pengetahuan dan pengalaman staf melalui pendidikan dan pelatihan, karena pendidikan dan pelatihan merupakan hal yang penting karena pendidikan adalah serangkaian aktivitas yang dirancang untuk meningkatkan bidan dalam kemampuan, keahlian, pengetahuan, pengalaman maupun perubahan sikap perilaku yang berkaitan dengan suatu pekerjaan. Dengan meningkatkan mutu pendidikan dan pelatihan berdasarkan kompetensi dan profesi akan menghasilkan tenaga kesehatan yang memiliki kinerja sesuai kebutuhan pelayanan kesehatandan dapat memuaskan pasien atau masyarakat. ${ }^{10}$

Aset yang paling penting yang harus dimiliki oleh organisasi adalah SDM yang berkualitas. SDM adalah orang-orang yang merancang dan menghasilkan suatu produk, serta merumuskan seluruh strategi dan tujuan organisasi. SDM inilah yang membuat sumber daya lainnya dapat berjalan, banyaknya keunggulan yang dimiliki oleh suatu organisasi tidak akan dapat menghasilkan produk yang bermutu jika didalamnya tidak disertai dengan SDM yang berkeahlian, berkompeten dan berdedikasi tinggi terhadap organisasi. ${ }^{11}$

Pengangkatan dan penempatan SDM dalam suatu jabatan struktural bidang kesehatan haruslah dilaksanakan berdasarkan prinsip profesionalisme sesuai standar kompetensi yang jelas. Sesuai dengan apa yang diamanatkan dalam peraturan Menteri Kesehatan Republik Indonesia Nomor 971/MENKES/PER/XI/2009 tentang Standar Kompetensi Pejabat Struktural Kesehatan. ${ }^{2}$ Dalam Bab III (Standar Kompetensi Struktural Kesehatan) pasal 3 ayat 1 Permenkes ini dikatakan bahwa pengangkatan pegawai ke dalam jabatan struiktural kesehatan dilakukan setelah memenuhi persyaratan kualifikasi serta standar koimpetensi jabatan yang akan dipangkunya melalui proses rekruitmen dan seleksi sesuai peraturan perundang-undangan. ${ }^{2}$

\section{Dana}

Dana atau finansial merupakan aspek yang sangat penting dalam menunjang pelaksanaan program IMD. Berdasarkan hasil penelitian Harmana diketahui bahwa pengajuan dana berdasarkan kebutuhan pada Asuhan Persalinan Normal, pengalokasian pendanaan untuk jasa pelayanan persalinan terkhusus IMD tidak ada dana tersendiri dimana pelaksanaan IMD termasuk rangkaian pelayanan dari asuhan persalinan normal. Pendanaan kesehatan adalah besarnya dana yang disediakan untuk menyelenggarakan program kesehatan atau dana untuk memanfaatkan berbagai upaya kesehatan yang diperlukan perorangan, keluarga, kelompok dan masyarakat. $^{14}$

Pendanaan peralatan kesehatan ditinjau dari dua aspek yaitu:

1. Penyediaan pelayanan kesehatan, yang dimaksud dengan pendanaan kesehatan dari sudut penyediaaan pelayanan (health provider) adalah besarnya dana yang harus disediakan untuk dapat menyelenggarakan upaya kesehatan.

2. Pemakaian jasa pelayanan, yang dimaksud dengan pendanaan kesehatan dari sudut pemakaian 
jasa pelayanan (health consumer) adalah besarnya dana yang harus disediakan untuk dapat memanfaatkan jasa pelayanan.

Dana sebagai syarat kelancaran sebuah program harus dialokasikan secara tepat, demikian juga kelancaran dalam proses penyediaan dan penggunaannya. ${ }^{10}$

\section{Sarana dan Prasarana}

Faktor sarana dan prasarana tidak dapat diabaikan dalam pelaksanaan program IMD. Keberhasilan pelaksanaan program IMD tidak hanya ditentukan SDM yang ada, akan tetapi dipengaruhi juga oleh sarana dan prasarana yang memadai. Secara teoritis sarana dan prasarana sangat menunjang kenyamanan pasien, perlengkapan yang menunjang dan lengkap.

Berdasarkan penelitian Ida Yunari Ristian bahwa sarana prasarana bersama-sama dengan kualitas pelayanan mempunyai pengaruh yang sangat kuat. Dengan demikian apabila sarana prasarana bagus yaitu apabila sarana prasarana/fasilitas yang dibutuhkan pasien tersedia secara representatif dan difungsikan/dimanfaatkan dengan benar maka kepuasan pasien akan maksimal. ${ }^{15}$

Hasil observasi dan wawancara mendalam untuk fasilitas kesehatan untuk aspek tampilan fisik standar bangunan secara fisik sudah baik, lokasi mudah dijangkau masyarakat, tetapi kebutuhan alat dan fasilitas mendukung dalam program IMD belum terpenuhi, seperti topi dan selimut bayi tidak tersedia di puskesmas, pustu maupun klinik bidan.

Keberhasilan persalinan dengan IMD juga ditentukan adanya fasilitas-fasilitas sebagai pendukung. UNICEF dan WHO bekerja sama mendorong negara-negara diseluruh dunia untuk menerapkan Pemasaran ASI, yaitu memperbaiki akses terhadap dukungan menyusui yaitu fasilitas kesehatan. $^{12}$ Ditetapkannya Keputusan Menteri Kesehatan Republik Indonesia No.450/MENKES/SK/ IV/2004 tentang Pemberian ASI secara eksklusif pada bayi di Indonesia, yang memuat sepuluh Langkah Menuju Keberhasilan Menyusui (LMKM) diantaranya berisi tentang rumah sakit/ rumah bersalin/ sarana pelayanan kesehatan yang berbasis sayang ibu dan anak diwajibkan mempunyai komunitas KP-ASI (kelompok pendukung asi) yaitu kelas ibu hamil, ibu menyusui, ibu sukses menyususi yang akan saling berbagi dan memberikan dukungan mengenai sukses menyusui. Klinik laktasi dimana didalamnya menginformasikan mengenai persalinan dengan IMD diamana manajemen klinik laktasi adalah tatalaksana yang diperlukan untuk menunjang keberhasilan menyusui terutama dimulai pada masa kehamilan, segera setelah persalinan dan pada masa menyusui selanjutnya. $^{2}$

Dalam upaya pencapaian tujuan pelaksanaan program IMD harus didukung oleh ketersediaaan sarana/fasilitas, tanpa sarana/fasilitas tugas pekerjaan spesifik tidak dapat diselesaikan sebagaimana mestinya, pekerjaaan tidak mungkin dapat dilaksanakan bahkan mengalami hambatan, ketersediaan sarana/fasilitas merupakan faktor penentuan tujuan program, pelaksana harus mendapat sumber yang dibutuhkan agar program berjalan lancar.

Fasilitas yang lengkap dan sesuai dengan standar yang ditetapkan (standar of personal and facilities) diharapkan dapat meningkatkan kualitas pelayanan kesehatan. Fasilitas kesehatan hendaknya dengan jumlah serta jenis yang memadai dan selalu dalam keadaan siap pakai. Untuk melakukan tindakan harus ditunjang fasilitas yang lengkap dan sebelumnya harus disediakan. ${ }^{11}$

\section{PROSES}

Perencanaan

Pada aspek perencanaan sudah terprogram dengan cukup baik tindakan awal yang harus dikerjakan dalam perencanaan IMD adalah memberikan pemahaman pada ibu tentang pentingnya IMD, sebab tindakan perencanaan IMD harus dikerjakan adalah agar ibu menyadari sepenuhnya manfaat atau pentingnya IMD.

Berdasarkan penelitian H.H. siregar yakni tindakan awal yang harus dikerjakan dalam perencanaan IMD adalah memberikan pemahaman pada ibu tentang pentingnya IMD. Sebab tindakan perencanaan IMD harus dikerjakan adalah agar ibu menyadari sepenuhnya manfaat atau pentingnya IMD. 
Tindakan IMD harus dilaksanakan di Puskesmas dan saranasarana pelayanan kesehatan lainnya. Tindakan IMD harus dilaksanakan saat ibu bersalin khususnya segera setelah bayi lahir. Yang akan melakukan tindakan IMD adalah bidan atau tenaga kesehatan lainnya yang kompeten pada saat ibu melahirkan. Cara melaksanakan tindakan IMD adalah melalui sosialisasi pada ibu dan keluarganya tentang pentingnya IMD sehingga setelah bayi lahir IMD dapat dilaksanakan sesuai prosedur/standar yang ditetapkan. ${ }^{16}$

Menurut Azwar, dari berbagai fungsi manajemen fungsi perencanaan merupakan fungsi terpenting, dimana fungsi lainnya baru berperan apabila fungsi perencanaan telah selesai dilaksanakan. Fungsi manajemen yang lain akan berjalan dengan baik apabila dapat selalu berpedoman pada perencanaan yang telah disusun sebelumnya. Perencanaan merupakan proses mendasar yang penting untuk memilih sasaran dan menetapkan bagaimana cara mencapainya, dimana dalam kegiatan tersebut terkandung dua konsep utama dalam kegiatan manajemen yaitu efektivitas dan efisien. ${ }^{17}$

\section{Pengorganisasian}

Kebijakan program IMD adalah mengacu pada standar asuhan persalinan normal serta pelaksanaan program ASI ekslusif, dimana prosedur tetap atau standar prosedur IMD ada dalam 60 langkah APN.

Pelaksanaan program IMD mempengaruhi komunikasi, sumber daya dan struktur organisasi yang bertugas mengimplementasikan kebijakan memiliki pengaruh terhadap pelaksanaan kebijakan IMD. Aspek dari struktur organisasi adalah standar operasional prosedur (SOP), dimana sosialisasi pelaksanaan IMD terdapat pada standar asuhan persalinan normal sebagai acuan kerja bidan.

Hal ini berpengaruh terhadap kualitas pelaksanaan IMD pada faktor sumber daya yaitu pada aspek pemahaman bidan terhadap IMD, sehingga pelaksanaan IMD belum sesuai dengan yang ditetapkan oleh pemerintah. Pemahaman bidan yang kurang terhadap IMD berdampak juga kepada pemahaman ibu bersalin mengenai IMD, dimana ibu hamil tidak mendapatkan informasi mengenai IMD pada saat kunjungan pemeriksaan kandungan.

Pada pelaksanaan program IMD di puskesmas Lubuk Buaya pengorganisasiannya belum optimal dilaksanakan, karena belum adanya sosialisasi IMD secara khusus yang diberikan oleh pihak Puskesmas kepada bidan pelaksana IMD. Informasi hanya diperoleh pada saat pelatihan APN yang diselenggarakan oleh Dinas Kesehatan Kota.

\section{Pelaksanaan}

Pada prosedur tetap IMD sudah tersedia yang tercatat pada Prosedur Tetap IMD yang menjelaskan tentang pedoman kerja dan petunjuk pelaksanaan IMD dengan masa berlakunya prosedur tetap dari tahun 2010. Bentuk SOP secara tertulis berupa selembaran SOP yang berisi tentang Asuhan Persalian Normal yang di dalamnya terdapat pengertian IMD dan tujuan IMD. Semua petugas bidan patuh dalam melaksanakan protap, tetapi masih terdapat bidan yang tidak mengetahui bentuk petunjuk SOP, sehingga dalam pelaksanaannya tidak sesuai dengan tahapan yang terdapat di dalam protap / prosedur tetap IMD.

Hasil penelitian Kartikasari et al (2014) menunjukkan bahwa pemahaman informan terhadap tujuan dan pentingnya prosedur tetap penting bagi peningkatan kualitas pelayanan dan dalam meningkatkan efektifitas suatu system pelayanan. Kecenderungan ini tentunya berpengaruh terhadap pelayanan yang diberikan. ${ }^{18}$ Menurut Azwar semakin dipatuhi pedoman atau prosedur tetap semakin baik pencapaian standar pelayanan. Dan kepatuhan dalam melaksanakan prosedur kerja akan dapat meningkatkan mutu pelayanan Sayang Ibu dan Bayi sehingga dapat menunjang keberhasilan pelayanan Puskesmas secara menyeluruh. ${ }^{17}$

Pelaksanaan IMD di puskesmas, pustu dan klinik bersalin BPM oleh bidan tidak tepat. Di dukung hasil observasi yang dilakukan oleh peneliti terhadap pelaksanaan IMD di puskesmas, pustu dan klinik bersalin BPM oleh bidan dapat di simpulkan bahwa pelaksanaan IMD tidak sesuai dengan 7 langkah pelaksanaan IMD yang dikeluarkan Kementrian Kesehatan Republik Indonesia, sebagian besar 
informan utama hanya melakukan sampai dengan bila bayi tidak memerlukan resusitasi, bayi ditengkurapkan di dada ibu dimana kulit bayi melekat pada kulit ibu (skin to skin contact) dengan posisi mata bayi setinggi putting susu ibu, keduanya di selimuti namun tidak diberi topi dan rata-rata bidan melakukannya maksimal 10 menit kemudian dilakukan asuhan bayi baru lahir.

\section{Monitoring IMD}

Evaluasi program IMD dengan melihat dan memonitoring kejadian yang terjadi dalam proses persalinan dengan melihat berapa banyak bayi lahir yang IMD dan berapa banyak yang tidak, sehingga diketahui secara pasti alasannya. Petugas medis di IGD, pustu dan BPM menyampaikan sebagian besar pengawasan dilakukan secara langsung dan insidentil, bila ada laporan atau kasus, bagian manajemen pelayanan mutu di Puskesmas datang untuk mengevaluasi. Dinas Kesehatan belum ada turun langsung memantau kegiatan di tiap ruangan, monitor dan evaluasi hanya pada tahap manajemen Puskesmas saja.

Monitoring dan evaluasi internal (Monevin) merupakan kegiatan rutin yang berkesinambungan dan harus terus menerus dilakukan. Pada dasarnya monevin merupakan pemantauan pelaksanaan kegiatan bukan suatu kegiatan untuk mencari kesalahan, tetapi membantu melakukan tindakan perbaikan secara terus menerus. Untuk monitoring dan evaluasi penyelenggaraan pelayanan kesehatan termasuk IMD tidak ada dilakukan secara khusus, tetapi sekaligus dengan evaluasi program KIA dari Dinas Kesehatan Kota pada tiap Puskesmas di kota Padang dengan adanya tim mutu dari tim audit internal.

Hasil wawancara mendalam kepada informan mengenai monitoring pelaksanaan program IMD di Puskesmas Lubuk Buaya kegiatan monitoring belum dilakukan secara terjadwal, hanya ada laporan pencatatan IMD sebulan sekali dalam pencatatan dan pelaporan persalinan. Kurangnya monitoring disebabkan karena tidak meratanya prosedur kerja yang diterima oleh bidan pelaksana IMD dan beberapa faktor penghambat dari pelaksaan program IMD.
Faktor-faktor penghambat tersebut adalah:

1. Tidak adanya sosialisasi IMD

2. Tidak adanya SOP yang jelas

3. Kurang optimal koordinasi berjenjang.

Berdasarkan hasil kegiatan penelitian Kiswati, pengawasan atau monitoring yang kurang baik dapat menghambat kegiatan pelayanan kesehatan sehingga supervisi perlu dilakukan secara berkala, bersifat objektif. ${ }^{13} \mathrm{Hal}$ ini sesuai dengan apa yang disampaikan oleh Handoko, supervisi berarti atasan mengarahkan secara sederhana untuk membuat atau mendapatkan apa yang diinginkan, yang harus mereka lakukan dengan menggunakan kemampuan motivasi, komunikasi dan kepemimpinan yang mengarahkan karyawan mengerjakan sesuatu yang ditugaskan kepada bawahan. ${ }^{19}$

\section{OUTPUT}

\section{Terlaksananya IMD}

Pada aspek pelaksanaan sudah cukup baik dengan melakukan pencatatan kegiatan secara dokumentasi dan lembar ceklist, buku laporan IMD dengan mencatat jumlah bayi yang di IMD. Namun, untuk pembagian tugas tidak dijelaskan dan bersifat situasional, bidan sebagai pelaksana IMD di kamar bersalin dan dokter sebagai pelaksanan di UGD. Pengarahan dan motivasi sudah diberikan melalui midwifery up date (MU) yang dilakukan oleh Ikatan Bidan Indonesia (IBI) setiap 3 bulan, seminar dan pelatihan sehingga tidak ditemukan kendala dalam pelaksanaan IMD.

Konsep teori yang dikembangkan oleh GR Terry menunjukkan bahwa setelah menetapkan tujuan dan menyusun rencana atau program untuk mencapainya, maka perlu merancang atau mengembangkan suatu organisasi yang akan dilaksanakan berbagai program tersebut secara sukses. Senada apa yang disampaikan oleh Terry, menurut Handoko bahwa untuk mencapai tujuan organisasi, setelah menentukan serangkaian tujuan dan menyusun rencana kegiatan, maka perlu merancang atau mengembangkan organisasi untuk dapat tercapai efektif dan efisien. ${ }^{19}$ 
Berdasarkan hasil penelitian Raharjo terlaksananya pemberian ASI secara dini dimulai dari peran petugas kesehatan dalam melakukan proses pertolongan persalinan, karena pada saat itulah peran petugas dalam pemberian ASI sejak dini bisa dilihat. ${ }^{20}$ Hal ini selaras dengan Depkes RI (2013), yang menyatakan bahwa bayi diberikan kepada ibunya segera setelah lahir dan diletakkan di dada ibunya agar bayi tersebut mencari puting ibunya sendiri sehingga proses IMD akan terjadi. ${ }^{21}$

Pada aspek pengawasan pelaporan dan pencatatan hasil pelaksanaan IMD dilaporkan ke Tim Bidan Koordinator (Bikor) melalui pelaporan perbulan. Monitoring dilakukan oleh Tim mutu dari tim audit internal, kepala ruangan atau bidan yang sedang bertugas dan kepala shift. Pelaksanaan kegiatan monitoring dilakukan setiap pertemuan 3 bulan sekali menjelang ada kegiatan tertentu atau moment tertentu. Evaluasi kegiatan dilakukan oleh bidan sampai bayi berhasil menemukan puting ibu kemudian dievaluasi oleh bidan penanggung jawab klinik melalui rapat setiap bulan dan laporan bayi. Masih banyak IMD yang kurang berhasil karena bayi sulit mencari puting ibu dan biasanya bayi langsung didekatkan ke puting.

\section{Tercapainya cakupan pelaksanaan IMD}

Harapan dalam pelaksanaan program inisiasi menyusu dini di wilayah kerja puskesmas lubuk buaya oleh responden kunci adalah tercapainya pelaksanaan pelayanan asuhan persalinan normal yang efektif dan efisien. Responden kunci sebagai pembuat kebijakan berharap seluruh petugas dan jejaring dalam sistem ini dapat memanfaatkan dan memberikan dukungan pada program yang telah di kembangkan dengan maksimal dengan tenaga bidan yang kompeten dan menguasai keahliannya.

Hasil wawancara dengan petugas pelaksana harian IGD,pustu dan BPM menyatakan pada saat IMD juga harus diperhatikan kondisi payudara ibu dalam pelaksanaannya berhasil atau tidak bayi menemukan puting susu ibu, serta pelayanan IMD yang dilaksanakan oleh bidan tidak harus selalu diselesaikan dengan cepat.

Pasien dan Keluarga pasien yang dirawat di puskesmas, pustu dan BPM menegaskan bahwa pelayanan di klinik bersalin pada dasarnya sudah bagus. Sebagai pengguna jasa mereka mengharapkan fasilitas dan kenyamanan di lingkungan puskesmas lebih diperhatikan dan semakin meningkatkan pelayanan IMD sesuai protap.

\section{SIMPULAN}

Komponen input pada pelaksanaan program inisiasi menyusu dini di Puskesmas Lubuk Buaya meliputi sumber daya manusia, pendanaan dan sumber sarana prasarana. Kebijakan yang sudah dibuat kurang mendapat pengawasan dalam pelaksanaannya. Proses Pelaksanaan IMD langsung dilakukan saat lahir tanpa boleh ditunda, selama 60 menit. Evaluasi dan pengawasan kegiatan pelaksanaan program IMD dilaksanakan setiap bulan melalui pencatatan dan pelaporan.

\section{SARAN}

Mengembangkan kepada sasaran pendukung program IMD kepada guru, ibu-ibu, kader, keluarga, konselor, motivator, PKK, Posyandu dan remaja putri SMA. Mengembangkan jaringan kader dan posyandu, mengembangkan pemberdayaan masyarakat dan keluarga lewat pertemuan dan pembekalan kader tentang IMD dan mengembangkan media promosi kepada masyarakat dan keluarga tentang IMD. Perlu dikembangkan pemberian konseling IMD kepada calon pengantin sebelum imunisasi, ibu hamil pada saat ANC di Puskesmas serta membuat leaflet tentang IMD untuk konseling bagi konselor dan motivator.

\section{UCAPAN TERIMA KASIH}

Peneliti berterima kasih kepada Ketua, pimpinan dan staf Puskesmas Lubuk Buaya Padang.

\section{DAFTAR PUSTAKA}

1. Roesli U. Panduan inisiasi menyusu dini plus ASI eksklusif. Jakarta: Pustaka Bunda; 2012.hlm.9-12.

2. Kementerian Kesehatan RI. Profil Kesehatan Indonesia. Jakarta: Kementerian Kesehatan Rl; 2015. hlm. 125

3. UNICEF. Levels \& Trends in Child Mortality: New York; 2015. hlm 30. 
4. Dinas Kesehatan Provinsi Sumatera Barat. Profil Kesehatan Provinsi Sumatera Barat Tahun 2014. Padang: Dinas Kesehatan Provinsi Sumatera Barat; 2016. Lampiran hlm. 119.

5. Setyawati P, Puspita D. Pengaruh inisiasi menyusu dini (IMD) terhadap lama pengeluaran plasenta pada kala III Persalinan di RB Paten Rejowinangun Utara Kotamadya Magelang: Jurnal Keperawatan Maternitas. 2013;1(2):78-84.

6. Edmond KM, Zandoh C, Quigley MA, AmengaEtego S, Owusu-Agyei S, Kirkwood BR. Delayed breastfeeding initiation increases risk of neonatal mortality: Pediatrics Official Journal of the American Academy Of Pediatrics. 2006;117(3): 380-6.

7. Horta BL, Victoria CG. Short-term effects of breastfeeding: a systematic review on the benefits of breastfeeding on diarrhoea and pneumonia mortality: Geneva: WHO; 2013.hlm.3.

8. Maryunani A. Inisiasi menyusu dini, ASI eksklusif dan manajemen laktasi. Jakarta: Trans Info Media; 2015.hlm.25.

9. Jaringan Nasional Pelatihan Klinik - Kesehatan Reproduksi (JNPK-KR). Pelatihan klinik asuhan persalinan normal. Jakarta: Departemen Kesehatan Republik Indonesia; 2013.hlm.6-10.

10.Komariah A. Pengelolaan pendidikan. Bandung: FIP - Administrasi Pendidikan; 2009. hlm.40.

11.Iskandar. Penelitian tindakan kelas. Jakarta: Gaung Persada (GP) Press; 2009. hlm.6.

12.UNICEF. Exclusive breastfeeding; 2015 (diakses 15 Mei 2019). Tersedia dari: http://www.Who.int/ ntrition/topics/ exclusive breasfeeding/en/.
13. Kiswati S. Studi tentang sikap konsumen atas merek tolak angin pada mahasiswa FE Undip. Semarang: Universitas Diponegoro; 2010.hlm.125.

14. Harmana, Tisa, Adisasmito W. Faktor-faktor yang mempengaruhi pembiayaan kesehatan daerah bersumber anggaran pendapatan dan belanja daerah tahun 2006. Jurnal Manajemen Pelayanan Kesehatan. 2016;09 (diakses 9 Juni 2017). Tersedia dari: https://journal.ugm.ac.id/index.php/ impk/ article/viewFile/2746/2468

15. Ristiani IY. Pengaruh sarana prasarana dan kualitas pelayanan terhadap kepuasan pasien. Jurnal Coopetition. 2017;VIII(1):55-66.

16. Siregar HH, Sriatmi A, Kartika Wulan LR. Evaluasi program inisiasi menyusu dini oleh bidan di rumah sakit Panti Wilasa Citarum Semarang. Kesehatan Masyarakat (e-Journal). 2014;2(2):103-9.

17. Azwar A. Pengantar administrasi kesehatan. Jakarta: Binarupa Aksara; 2010.hlm.55.

18. Kartikasari D, Dewanto A, Rochman F. Pengaruh kualitas layanan terhadap kepuasan dan kepercayaan di Rumah Sakit Bunda Kandangan Surabaya. Jurnal Aplikasi Manajemen (JAM); 2014:454-63.

19. Handoko. Manajemen personalia sumber daya manusia. Edisi ke-2. Jakarta: 2014.hlm.89.

20. Raharjo B. Profil ibu dan peran bidan dalam praktik inisiasi menyusu dini dan asi eksklusif. Jurnal Kemas. 2014;10(1):53 - 63.

21.Departemen Kesehatan RI. Manajemen laktasi: buku panduan bagi bidan dan petugas kesehatan di puskesmas. Jakarta: Direktorat Gizi Masyarakat; 2013. hlm.5. 